\title{
Determination of Cadmium in Spring Water by Graphite- Furnace Atomic Absorption Spectrometry after Coprecipitation with Ytterbium Hydroxide
}

\author{
Kousuke ATSUmI, Tomoharu Minami, and Joichi UeDA \\ Faculty of Education, Kanazawa University, Kakumamachi, Kanazawa 920-1192, Japan
}

\begin{abstract}
A coprecipitation method with ytterbium hydroxide was studied for the determination of cadmium in water samples by graphite-furnace atomic absorption spectrometry. Up to $40 \mathrm{ng}$ of cadmium in water samples was quantitatively coprecipitated with ytterbium hydroxide at $\mathrm{pH} 8.0$ - 11.2. The concentration factor was 100 fold. The coprecipitated cadmium was sensitively determined without any influence of ytterbium and the calibration curve was linear from 0.1 to $4 \mathrm{ng} / \mathrm{mL}$ of cadmium. The detection limit (signal/noise = 2) was $2.9 \mathrm{pg} / \mathrm{mL}$ in $100 \mathrm{~mL}$ of the initial sample solution. Twenty-nine diverse ions tested did not interfere with the determination in at least a 10000-fold mass ratio to cadmium. The proposed method was successfully applied to the determination of cadmium in spring water.
\end{abstract}

(Received February 23, 2005; Accepted May 2, 2005)

Since long ago, spring water has been used for therapeutic bathing and drinking cures. However, toxic materials are sometimes contained in them. Thus, analyses of toxic materials in spring water are required for accurately access pollution levels, especially in the case of drinking cures. This time, we focused on cadmium, which is one of highly toxic metals, and tried to propose a simple and reproducible determination method of trace cadmium in spring water.

Coprecipitation with metal hydroxides has been widely used for the concentration of trace metal ions in water, associated with various determination techniques. ${ }^{1,2}$ In combination with the graphite-furnace atomic absorption spectrometry, which is prone to suffer from a matrix effect, it is desirable to use such a coprecipitant so that the separation factor for the alkali and alkaline earth metals is sufficient, and the presence of the coprecipitant, itself, does not cause background absorption. We have been investigating a new coprecipitant of cadmium in spring water for the graphite-furnace atomic absorption spectrometric determination, and have found that ytterbium hydroxide has a good collecting ability for cadmium and hardly coprecipitates matrix ions, such as sodium, potassium, magnesium, and calcium. Also, the coprecipitant dissolves easily in acids, and does not cause interference in the cadmium determination.

Until now, several coprecipitants, such as lanthanum phosphate, ${ }^{3}$ pyrrolidine-dithiocarbamate (APDC) of cobalt, ${ }^{4}$ copper, ${ }^{5,6}$ and iron(III), ${ }^{5,6}$ diethyl-dithiocarbamate (DDTC) of zinc $^{7,8}$ and nickel, ${ }^{9}$ and hydroxides of iron(III), ${ }^{10}$ hafunium,,${ }^{11}$ indium, ${ }^{12-15} \operatorname{tin}(\mathrm{IV}),{ }^{16}$ gallium, ${ }^{17}$ and samarium, ${ }^{18}$ have been proposed for the preconcentration of cadmium prior to a graphite-furnace atomic absorption spectrometric determination. However, the use of cobalt $\mathrm{APDC}^{4}$ requires a long digestion period of the precipitate in order to simplify the sample matrix. Although nickel DDTC $^{9}$ is dissolved somewhat easily, it is necessary to use nitric acid and acetone for dissolution.

APDC of copper ${ }^{5,6}$ and iron(III) $)^{5,6}$ and zinc DDTC ${ }^{7,8}$ are also dissolved only slowly. In the case metal hydroxides, the use of indium and gallium as carrier elements causes serious background absorption. To eliminate this background absorption, therefore, the volatilization of indium and gallium as bromide ${ }^{12,15}$ and chloride, ${ }^{17}$ respectively, during the ashing stage was tried. For indium, the use of a minimal amount of indium $^{13,14}$ was also tried for a coprecipitation procedure. The method using tin(IV) ${ }^{16}$ takes long time in order to remove tin(IV) as stannic acid, because the tin(IV) carrier causes large background absorption. The use of hafnium hydroxide ${ }^{11}$ is expensive and that of iron(III) hydroxide ${ }^{10}$ can not avoid the coprecipitation of large amounts of alkaline earth metals, which may interfere with the cadmium determination. Although samarium hydroxide ${ }^{18}$ is a good collector, the optimal $\mathrm{pH}$ for the coprecipitation is high ( $\mathrm{pH}$ 12.2), and hence not easily handled. The method proposed here overcomes those weak points, and was successfully applied to the determination of cadmium in spring water.

\section{Experimental}

\section{Apparatus}

A Hitachi 170-70 Zeeman atomic absorption spectrometer with a Hitachi cadmium hollow-cathode lamp was used for atomic absorption measurements. The optimum operation conditions, which were studied using a solution obtained by coprecipitation according to the recommended procedure from a distilled water containing $40 \mathrm{ng}$ of cadmium, are summarized in Table 1. For pH measurements, a Toa Model HM-5BS glasselectrode $\mathrm{pH}$ meter was used.

\section{Reagents}

A solution containing about 1 or $10 \mathrm{mg} / \mathrm{mL}$ of cadmium or ytterbium, respectively, was prepared by dissolving metal nitrate (Wako Chemicals) in a small amount of concentrated 
Table 1 Recommended operating conditions for the atomic absorption spectrometer

\begin{tabular}{ll}
\hline Analytical wavelength & $228.8 \mathrm{~nm}$ \\
Lamp current & $6 \mathrm{~mA}$ \\
Slit width & $\mathrm{No.} 3(2.2 \mathrm{~nm})$ \\
Argon gas flow rate & \\
$\quad$ Sheath gas & $3 \mathrm{~L} \mathrm{m^{-1 }}$ \\
$\quad$ Carrier gas & $0 \mathrm{~L} \mathrm{~min}{ }^{-1}$ \\
Injection volume & $10 \mu \mathrm{L}$ \\
Cuvette & Uncoated tube type \\
& graphite furnace \\
Drying conditions & $20 \mathrm{~A}\left(\mathrm{ca} .100^{\circ} \mathrm{C}\right), 30 \mathrm{~s}$ \\
Ashing conditions & $50 \mathrm{~A}\left(\mathrm{ca} .400^{\circ} \mathrm{C}\right), 40 \mathrm{~s}$ \\
Atomizing conditions & $200 \mathrm{~A}\left(\mathrm{ca} .1900^{\circ} \mathrm{C}\right), 5 \mathrm{~s}$ \\
\hline
\end{tabular}

nitric acid and diluting with distilled water. The concentrations of both cadmium and ytterbium were determined by complexometric titration using Xylenol Orange as an indicator. All other reagents used were of guaranteed reagent grade.

\section{Recommended procedure}

To a sample solution (up to $100 \mathrm{~mL}$ ) containing $1-40 \mathrm{ng}$ of cadmium, $25 \mathrm{mg}$ of ytterbium are added, and the $\mathrm{pH}$ of the solution is adjusted to about 9.5 with a $0.1 \mathrm{~mol} / \mathrm{L}$ sodium hydroxide solution, using a $\mathrm{pH}$ meter. To settle the produced precipitate, the solution is allowed to stand for about $30 \mathrm{~min}$; the precipitate is collected on a Toyo Roshi PTFE membrane filter (pore size $0.5 \mu \mathrm{m}$, diameter $25 \mathrm{~mm}$ ), and washed with a small amount of distilled water. After the precipitate is dissolved with $4 \mathrm{~mL}$ of $3 \mathrm{~mol} / \mathrm{L}$ nitric acid, a final volume of the solution is made up to 5 or $10 \mathrm{~mL}$ with distilled water.

The atomic absorbance of cadmium is measured under the operating conditions given in Table 1. A blank, using distilled water as a sample, is run using the same procedure as for the sample solution. In this work, the blank could be neglected in most instances because it was extremely small.

\section{Results and Discussion}

Study of the optimum conditions for coprecipitation

Effect of the $\mathrm{pH}$ on coprecipitation. The effect of the $\mathrm{pH}$ on coprecipitation with ytterbium hydroxide was studied with a solution containing $40 \mathrm{ng}$ of cadmium. The maximum and almost constant recoveries were obtained in the $\mathrm{pH}$ range of 8.0 - 11.2. The precipitate of ytterbium hydroxide, obtained as mentioned above, at a $\mathrm{pH} 9.0$ was bulky, and hence easily handled. Therefore, the $\mathrm{pH}$ was adjusted to about 9.5 with a 0.1 $\mathrm{mol} / \mathrm{L}$ sodium hydroxide solution in further experiments.

Effect of the amount of coprecipitant. According to the recommended procedure, the necessary amount of ytterbium for coprecipitation was examined with a sample solution (up to 500 $\mathrm{mL}$ ) containing $10 \mathrm{ng}$ of cadmium. The required amount of ytterbium for the quantitative coprecipitation increased along with increasing the sample volume, and $25 \mathrm{mg}$ of ytterbium was needed for at least up to $500 \mathrm{~mL}$ of the sample solution. Since the atomic absorption of cadmium was not affected by the presence of up to $74 \mathrm{mg}$ of ytterbium in the final sample solution $(5 \mathrm{~mL}), 25 \mathrm{mg}$ of ytterbium was used in subsequent experiments. The highest concentration factor in this experiment was 100 when the initial and final sample volumes were 500 and $5 \mathrm{~mL}$, respectively.

Effect of the standing time of the precipitate. The recoveries of
Table 2 Recoveries of some ions by ytterbium hydroxide

\begin{tabular}{lccccc}
\hline \multicolumn{1}{c}{ Ion } & Added $/ \mu \mathrm{g}$ & Rec., $\%$ & Ion & Added/ $\mu \mathrm{g}$ & Rec., \% \\
\hline $\mathrm{Na}^{+}$ & 50000 & 1.8 & $\mathrm{Cu}^{2+}$ & 1 & 101.3 \\
$\mathrm{~K}^{+}$ & 50000 & 2.1 & $\mathrm{Cr}^{3+}$ & 0.5 & 96.0 \\
$\mathrm{Mg}^{2+}$ & 50000 & 0.3 & $\mathrm{Cr}^{\mathrm{VI}}$ & 0.5 & 97.1 \\
$\mathrm{Ca}^{2+}$ & 50000 & 0.0 & $\mathrm{Mo}^{\mathrm{VI}}$ & 1 & 61.1 \\
$\mathrm{Sn}^{4+}$ & 2 & 97.0 & $\mathrm{Mn}^{2+}$ & 0.2 & 99.9 \\
$\mathrm{~Pb}^{2+}$ & 0.5 & 98.2 & $\mathrm{Co}^{2+}$ & 4 & 100.1 \\
$\mathrm{Bi}^{3+}$ & 10 & 98.9 & $\mathrm{Ni}^{2+}$ & 4 & 97.0 \\
\hline
\end{tabular}

The coprecipitation of the ions was carried out from about $100 \mathrm{~mL}$ of aqueous solution at a $\mathrm{pH}$ about 9.5. The final volume was made up to $10 \mathrm{~mL}$.

cadmium were little influenced by the standing time of the precipitate. Thus, almost $100 \%$ recoveries were obtained within $20 \mathrm{~min}$ after the formation of ytterbium hydroxide, and the recovered amounts remained unchanged for at least $2 \mathrm{~h}$ of standing.

Dissolution of ytterbium hydroxide. Ytterbium hydroxide dissolves easily in all common mineral acids. The effects of the concentration of nitric and hydrochloric acid on the peak height of cadmium were examined. Since the peak heights of cadmium were nearly constant in the ranges of $0.8-3.0$ and 0.6 - $1.8 \mathrm{~mol} / \mathrm{L}$, respectively, $4 \mathrm{~mL}$ of $3.0 \mathrm{~mol} / \mathrm{L}$ of nitric acid was used for the dissolution of the precipitate.

\section{Calibration curve}

Using $100 \mathrm{~mL}$ of a sample solution, a calibration curve was prepared according to the recommended procedure. The final volume was made up to $10 \mathrm{~mL}$. As a result, a straight line passing through the origin was obtained for $0.1-4 \mathrm{ng} / \mathrm{mL}$ of cadmium. The relative standard deviation was $3.2 \%$ for $10 \mathrm{ng}$ of cadmium in about $100 \mathrm{~mL}$ of the sample solution (five observations) and the detection limit (signal to noise ratio of two) was $2.9 \mathrm{pg} / \mathrm{mL}$ in $100 \mathrm{~mL}$ of the initial sample solution.

\section{Recoveries of some metal ions by ytterbium hydroxide}

The selectivity of ytterbium hydroxide as a coprecipitant was investigated according to the coprecipitation procedure indicated in the recommended procedure, determining the recovery percentages of some metal ions. The recovery of each metal ion was determined by graphite-furnace atomic absorption spectrometry. For sodium, potassium, magnesium, and calcium, however, flame atomic absorption spectrometry was used. As shown in Table 2, sodium, potassium, magnesium, and calcium were hardly collected. Other ions, such as tin(IV), lead, bismuth(III), copper, chromium(III, VI), manganese, cobalt, and nickel, could be coprecipitated quantitatively, which indicates that ytterbium hydroxide is applicable to the concentration of those ions.

\section{Interferences}

The influence of 29 diverse ions was examined using $10 \mathrm{ng}$ of cadmium in about $100 \mathrm{~mL}$ of the sample solution. Table 3 shows that large amounts sodium, potassium, magnesium, calcium, chloride, sulfate, hydrogencarbonate, metaborate, metasilicate, and bromide did not interfere with the determination. No other ions tested produced any interference effect, even at a concentration 10000-times the mass of the cadmium present.

Recovery of cadmium from spiked water samples

The utility of the present method was evaluated by examining 
Table 3 Effect of diverse ions on the determination of $10 \mathrm{ng}$ of cadmium

\begin{aligned} & \hline Mass ratio ${ }^{\mathrm{a}}[\mathrm{Ion}] /[\mathrm{Cd}] \multicolumn{1}{c}{$ Ion } \\ & \hline 270000000 $\mathrm{Cl}^{-} \\ & 170000000 \mathrm{Na}^{+} \\ & 100000000 \mathrm{SO}_{4}^{2-} \\ & 20000000 \mathrm{HCO}_{3}{ }^{-} \\ & 15000000 \mathrm{~K}^{+} \\ & 10000000 \mathrm{Mg}^{2+}, \mathrm{Ca}^{2+}, \mathrm{HBO}_{2} \\ & 3000000 \mathrm{Br}^{2} \mathrm{H}_{2} \mathrm{SiO}_{3} \\ & 300000, \mathrm{Sr}^{2+} \\ & 100000 \mathrm{Li}^{+}, \mathrm{Ba}^{2+}, \mathrm{Al}^{3+}, \mathrm{Zn}^{2+}, \mathrm{Mn}^{2+}, \mathrm{Fe}^{2+}, \mathrm{Fe}^{3+} \\ &, \mathrm{F}^{-}, \mathrm{I}^{-}, \mathrm{S}_{2} \mathrm{O}_{3}^{2-} \\ &, \mathrm{Pb}^{2+}, \mathrm{Cu}^{2+}, \mathrm{Mo}^{\mathrm{VI}}, \mathrm{Cr}^{3+}, \mathrm{Cr}^{\mathrm{VI}}, \mathrm{Co}^{2+}, \mathrm{Ni}^{2+} \\ &, \mathrm{HPO}_{4}^{2-} \\ &$\hline\end{aligned}

The coprecipitation was carried out from about $100 \mathrm{~mL}$ of the aqueous solution at a pH of about 9.5 , making up the final volume to $10 \mathrm{~mL}$. a. The errors are within $\pm 5 \%$.

the recoveries of cadmium from distilled and spring water spiked with cadmium according to the recommended procedure. As the results show in Table 4, down to $10 \mathrm{pg} / \mathrm{mL}$ of cadmium in up to $500 \mathrm{~mL}$ of the initial sample solution was recovered quantitatively. The highest concentration factor was 100 -fold when the initial and final volumes were 500 and $5 \mathrm{~mL}$, respectively.

\section{Determination of cadmium in spring water}

Based on the results obtained from the above-mentioned experiments, the determination of cadmium in spring water (located in Ishikawa Prefecture) was tried. The samples were filtered through a Toyo Roshi TM-2p membrane filter (pore size $0.45 \mu \mathrm{m})$ and analyzed as soon as possible after sampling. As shown in Table 5, the results obtained by calibration and standard addition methods were in good agreement. The time required for the determination was about $50 \mathrm{~min}$.

\section{Conclusion}

From this study, ytterbium hydroxide is recommended as a coprecipitant prior to the determination of cadmium in spring water by graphite-furnace atomic absorption spectrometry, owing to its excellent collecting ability and selectivity. Also, ytterbium hydroxide can be formed at relatively low $\mathrm{pH}$ ( $c a$. 9.5); the formed precipitate is bulky, and hence easily handled.

\section{References}

1. A. Mizuike, "Enrichment Techniques for Inorganic Trace Analysis", 1983, Springer-Verlag, Berlin, 56 - 66.

2. Yu. A. Zolotov and N. K. Kuz'min, "Preconcentration of Trace Elements", in "Comprehensive Analytical Chemistry", ed. G. Svehla, 1990, Vol. 25, Elsevier, Amsterdam, 79 - 94.

3. S. Kagaya, Y. Hosomori, H. Arai, and K. Hasegawa, Anal. Sci., 2003, 19, 1061.

4. E. A. Boyle and J. M. Edmond, Anal. Chim. Acta, 1977, 91, 189.

5. R. W. Dabeka and A. D. Mchenzie, Can. J. Spectrosc.,
Table 4 Recovery of cadmium from spiked water samples

\begin{tabular}{ccccc}
\hline $\begin{array}{c}\text { Sample volume/ } \\
\mathrm{mL}\end{array}$ & $\begin{array}{c}\text { Final volume/ } \\
\mathrm{mL}\end{array}$ & $\begin{array}{c}\text { Cd added/ } \\
\mathrm{ng}\end{array}$ & $\begin{array}{c}\text { Cd found/ } \\
\mathrm{ng}\end{array}$ & $\begin{array}{c}\mathrm{RSD}, \\
\%\end{array}$ \\
\hline $\begin{array}{c}\text { Distilled water } \\
500\end{array}$ & 5 & & & \\
500 & 5 & 30 & 29.9 & 3.9 \\
$\begin{array}{c}\text { Spring water } \\
\text { (100 }\end{array}$ & 10 & 1 & 0.96 & 3.9 \\
100 & 10 & 30 & 29.8 & 4.4 \\
500 & 5 & 1 & 0.95 & 4.8 \\
500 & 5 & 30 & 29.5 & 4.6 \\
\hline
\end{tabular}

The recoveries obtained are the average of three replicate determinations.

a. Recoveries of cadmium were calculated by subtracting the peak height due to spring water from it due to spring water spiked with cadmium.

Table 5 Results from the determination of cadmium in springwater samples

\begin{tabular}{lccc}
\hline \multirow{2}{*}{$\begin{array}{c}\text { Location of } \\
\text { sampling point }\end{array}$} & Calibration method & & $\begin{array}{c}\text { Standard addition } \\
\text { method }\end{array}$ \\
\cline { 2 - 2 } $\begin{array}{l}\text { The fountainhead } \\
\text { of spring }\end{array}$ & & & \\
$\quad$ Yuwaku & 0.011 & \\
Awazu & 0.031 & \\
Asanogawa No. 1 & 0.014 & \\
Asanogawa No. 2 & 0.013 & 0.031 \\
Katayamazu & 0.021 & 0.014 \\
\hline
\end{tabular}

The sample volume taken was $100 \mathrm{~mL}$ and the final volume was made up to $10 \mathrm{~mL}$. The results obtained are the average of three replicate determinations.

1986, 31, 44.

6. R. W. Dabeka, Sci. Total Environ., 1989, 89, 271.

7. F. Sugimoto, Y. Maeda, and T. Azumi, Nippon Kaisui Gakkaishi, 1990, 44, 124.

8. F. Sugimoto, Y. Maeda, and T. Azumi, Kankyo Gijyutsu, 1990, 19, 27.

9. H. Sato and J. Ueda, Anal. Sci., 2000, 16, 299.

10. V. Hudnik, S. Gomiscek, and B. Gorenc, Anal. Chim. Acta, 1978, 98, 39.

11. J. Ueda and N. Yamazaki, Bull. Chem. Soc. Jpn., 1986, 59 , 1845.

12. M. Hiraide, Z. S. Chen, and H. Kawaguchi, Mikrochim. Acta, 1997, 127, 119.

13. M. Hiraide, T. Usami, and H. Kawaguthi, Anal. Sci., 1992 8,31 .

14. M. Hiraide, Z. S. Chen, and H. Kawaguchi, Anal. Sci., 1995, 11, 333.

15. Z. S. Chen, M. Hiraide, and H. Kawaguchi, Bunseki Kagaku, 1993, 42, 759.

16. M. Hiraide, Z. S. Chen, K. Sugimoto, and H. Kawaguchi, Anal. Chim. Acta, 1995, 302, 103.

17. M. Hiraide and J. Hori, Anal. Sci., 1998, 14, 429.

18. S. Saracoglu, M. Soylak, and L. Elci, Talanta, 2003, 59, 287. 